\title{
Maternal Blood Milk Saliva Sample Selection and the Transmission of Hepatitis B Virus Infectious Research
}

\author{
Chenyan Huang1,2*, Youbing Fang ${ }^{3}$ \\ ${ }^{1}$ Affiliated Maternity and Child Institute, Anhui Medical University, Hefei, China \\ ${ }^{2}$ Anhui Medical University, Hefei, China \\ ${ }^{3}$ The First Affiliated Hospital of Anhui Medical University, Hefei, China \\ Email: ^1365558179@qq.com
}

How to cite this paper: Huang, C.Y. and Fang, Y.B. (2019) Maternal Blood Milk Saliva Sample Selection and the Transmission of Hepatitis B Virus Infectious Research. Open Journal of Obstetrics and Gynecology, 9, 363-370. https://doi.org/10.4236/ojog.2019.93037

Received: October 29, 2018

Accepted: March 5, 2019

Published: March 8, 2019

Copyright ( 2019 by author(s) and Scientific Research Publishing Inc. This work is licensed under the Creative Commons Attribution International License (CC BY 4.0).

http://creativecommons.org/licenses/by/4.0/

\section{cc) (i) Open Access}

\begin{abstract}
Background: Hepatitis B is an infectious disease, which is a main way of vertical transmission of infectious HBV between mother and infant. Hepatitis B virus infection is always a hot topic of social concern, especially in China. The paper studies hepatitis B virus in maternal blood, breast milk, saliva of hepatitis B virus infection model (HBV-M) in Hefei city, Anhui province, PRC. HBV-DNA load and related data in Hefei city are used for risk assessment of the transmission of hepatitis B virus to provide evidence for evidence-based medicine and scientific guidance of infant feeding patterns. Methods: On the principle of informed consent, inpatient hepatitis B maternal blood 695, breast milk, saliva 614,169 copies were used as the object of analysis, using the ELISA method for the detection of HBV-M, using real-time fluorescence quantitative PCR detection of HBV-DNA load. We analyze HBsAg in saliva, milk, the positive rate of HBV-DNA and HBV-M in serum, saliva, milk, and explore the positive rate of HBV-DNA and serum HBV-DNA load correlation. Results: At the age of $18-44$ years old perinatal women, HBV-DNA positive rates of maternal serum, breast milk, saliva were 157 cases in A group HBsAg, HBeAg positive: 99.36\%, 88.06\%, 96.77\%; in 312 cases in group B, HBeAb HBsAg, HBcAb positive: 17.63\%, 2.93\%, 54.67\%; 69 cases in C group HBsAg, $\mathrm{HBcAb}$ positive: $63.77 \%, 27.27 \%, 28.57 \%$; D group of 71 patients with simple $\mathrm{HBcAb}$ positive: $12.68 \%, 3.13 \%, 0 \%$; E group and 86 cases in control group HBVM: $1.16 \%, 0 \%, 0 \%$. According to the serum and milk testing of Group A and Group B, HBV-DNA chi-square is $\chi^{2}=237.45, \mathrm{P}<0.01$; there is a significant difference in serum and saliva; HBV-DNA chi-square $\chi^{2}$ $=289.49, \mathrm{P}<0.01$, the difference has statistical significance. Conclusion: 1 ) HBV-DNA load high maternal blood, breast milk, saliva are potentially persistent hepatitis B virus infection risk, especially infectious blood. 2) Of ma-
\end{abstract}


ternal milk, saliva and blood HBV-DNA HBV-DNA load were positively correlated $(r=0.96 ; \mathrm{P}<0.01)$; with the serum HBV-DNA load increasing, breast milk and saliva HBV-DNA positive rates were increased and infectivity enhanced. 3) Maternal blood, breast milk, saliva specimens for any HBV-DNA $\geq 1000$ copies/ml are not breastfeeding. 4) The mother who carries the hepatitis $B$ virus cannot do maternal infant feeding, and deep kiss intimate contact, in order to prevent blood, saliva and other ways of infection of hepatitis B virus. 5) Saliva testing is instead of milk inspection, because saliva is easier; salivary HBV-DNA load is relatively constant and less infectious. 6) Trimester detection of salivary HBV DNA load, can objectively evaluate the safety of breast-feeding, maternal and child between assessment of persistent infection of hepatitis B virus risk, for infant feeding patterns, maternal contact mode, eugenics and provide evidence of evidence-based medicine. 7) Women carrying hepatitis B virus in lactation do regularly dynamic detection in maternal blood, saliva, milk, HBV-DNA can replace HBsAg as mother-to-child infection risk assessment. 8) Blood, milk and saliva detection of carriers in HBV-M mode and HBV-DNA load, can guide the clinical treatment, block mother infant vertical transmission of hepatitis $B$ virus ways, reduce the incidence of hepatitis $B$, improve the perinatal health care system, all of which have important clinical implications. 9) The study found that hepatitis B virus from the blood can enter into the saliva through the oral mucosa; hepatitis B virus can directly pass the oral mucosa into the blood, which needs to be further studied in the future.

\section{Keywords}

Infection, Hepatitis B Virus, Breast Milk, Saliva, HBV-DNA, Load Mucositis, Risk Assessment

\section{Introduction}

Hepatitis B is a widespread public health infectious disease, by blood transfusion, sex, maternal and insect bites and other means of communication. HBV, neonatal infection of hepatitis B virus after $90 \%$ or more will turn for the hepatitis B virus carriers, who in adult lives can progress to cirrhosis and hepatocellular carcinoma [1] [2]. Milk, saliva of hepatitis B virus (Hepatitis B Virus, referred to as HBV) of infectious is always the hot issue of social concern, especially in China. The paper studies hepatitis B virus in maternal blood, breast milk, saliva of hepatitis B virus infection model (HBV-M) in Hefei city, Anhui province, PRC. HBV-DNA load and related data in Hefei city are used for risk assessment of the transmission of hepatitis B virus to provide evidence for evidence-based medicine and scientific guidance of infant feeding patterns.

\section{Methods}

\subsection{Materials}

Based on the principle of informed consent, from August 2008 to December 
2011, 695 patients, aged at 18 to 44 years old, average age 29.6, in Hefei carrying hepatitis B virus in maternal blood, breast milk, and saliva are as research objects of the study, whom are chosen by Hefei Maternal and Child Health Hospital. Research methods in informed consent principle hospitalized hepatitis B maternal blood 695, breast milk 614, saliva 169 copies as the analysis object, using the ELISA method for the detection of HBV-M, using real-time fluorescence quantitative PCR detection of HBV-DNA load. According to maternal HBVM were divided into five groups: A group, $\mathrm{HBsAg}, \mathrm{HBeAg}, \mathrm{HBcAb}$ was positive in 157 cases; $\mathrm{B}$ group $\mathrm{HBsAg}, \mathrm{HBeAb}, \mathrm{HBcAb}$ was positive in 312 cases; $\mathrm{C}$ group $\mathrm{HBsAg}, \mathrm{HBcAb}$ was positive in 69 cases; in group $\mathrm{D}$ ( $\mathrm{HbsAg}$ ) $\mathrm{HBcAb}$ was positive in 71 cases; E group: HBV-M negative in 86 cases.

Milk collection base postnatal colostrum juice $5 \mathrm{ml}$ by ward nurses collected, please be willing to participate in the study of 614 cases of maternal milk nipple with sterile saline after disinfection, using sterile tubes for milk, colostrum collected $5 \mathrm{ml}$, collected in a test tube, all tubes, centrifuge tube, suction head and a storage vessel have been high pressure sterilization, specimens were collected in $4000 \mathrm{r} / \mathrm{min}$ centrifugal $10 \mathrm{~min}$, abandon the fat milk, whey and middle hepatitis $B$ virus markers and quantitative detection of HBV-DNA.

Maternal saliva collected from 2 to 4 days postpartum, early in the morning, please be willing to participate in the study of hepatitis B maternal mouth with water after $\mathrm{Su}$, rest 10 minutes, abandoned to the $\mathrm{Su}$ mouth after the first mouth saliva, saliva secretion collection continued to $5 \mathrm{ml}$ to clean the inside the tube, 4000 r/min centrifugal after 10 minutes, take saliva supernatant. All tubes, centrifuge tube, suction head and a storage container prior to use by autoclaving, all operations are strictly in accordance with the principles of asepsis of.

\subsection{Instruments, Experimental, Positive Standard}

HBVM positive in accordance with the Beijing cosmos pharmaceutical company limited by enzyme-linked immunosorbent assay (ELISA) kit for hepatitis B specification standard microplate judgment, at the same time with the ABI series instrument real time fluorescent quantitative PCR method for detecting maternal serum, breast milk, saliva HBV-DNA load; specimens studied are all fresh specimens, HBV-DNA produced by ABI company the PE-5700 fluorescence quantitative PCR instrument, HBV-DNA PCR fluorescence reagent kit for the Xiamen Anpuli biological engineering company limited to provide, in strict accordance with the manual operation, positive judgement standard: HBV-DNA $\geq 1000$ copies/ml as HBV-DNA positive, direct report quantitative results; the measured value $\mathrm{HBV}$-DNA $<1000$ copies/ml, according to the reagent specification judgment is negative, report HBV-DNA $<1000$ copies $/ \mathrm{ml}$.

Statistical method and its application to specimens of the experimental operating system data collection, using SPSS 17 software package for data processing, a variety of specimens in HBVM, the positive rate of HBV-DNA and study data comparison, by $\chi^{2}$ test $^{13}$. 


\section{Results}

695 Cases of maternal serum, breast milk, saliva samples were collected, a comprehensive set of relatively small, so we are faithfully reported cases of actual research, sample testing data, statistical results as shown in Table 1, Table 2, Table 3.

From Table 1 that participated in a study of maternal serum, breast milk, saliva, the positive rates of HBV-DNA is respectively A group; 99.36\% (156/157), $88.06 \%$ (118/134), $96.77 \%$ (60/62); in group B $17.63 \%$ (55/312), 2.93\% (9/307), $54.67 \%$ (41/75); in group C $63.77 \%$ (44/69), $27.27 \%$ (15/55), 28.57\% (6/21); in group D12.68\% (9/71), 3.13\% (1/32), 0\% (0/3); in group E1.16\% (1/86), 0\% (0/86), 0\% (0/6); A group and B group, serum and Breast milk HBV-DNA chi-square $\chi^{2}=237.45, \mathrm{P}<0.01$, the difference has statistical significance; $\mathrm{A}$ group and B group, serum and saliva HBV-DNA chi-square $\chi^{2}=289.49, \mathrm{P}<$ 0.01 , the difference has statistical significance.

From Table 2 and graph experimental data were found in group B, group C, group D, group E in maternal serum, milk, saliva HBV-DNA load is much lower than that in A group maternal, research group A maternal body active replication of the HBV, A group in the parturients with hepatitis B virus DNA load is B HBV-DNA load average maternal milk 87.45 times $(89,200 / 1020)$.

Table 1. The perinatal period 695 cases of maternal serum, breast milk, saliva of hepatitis B markers test results list.

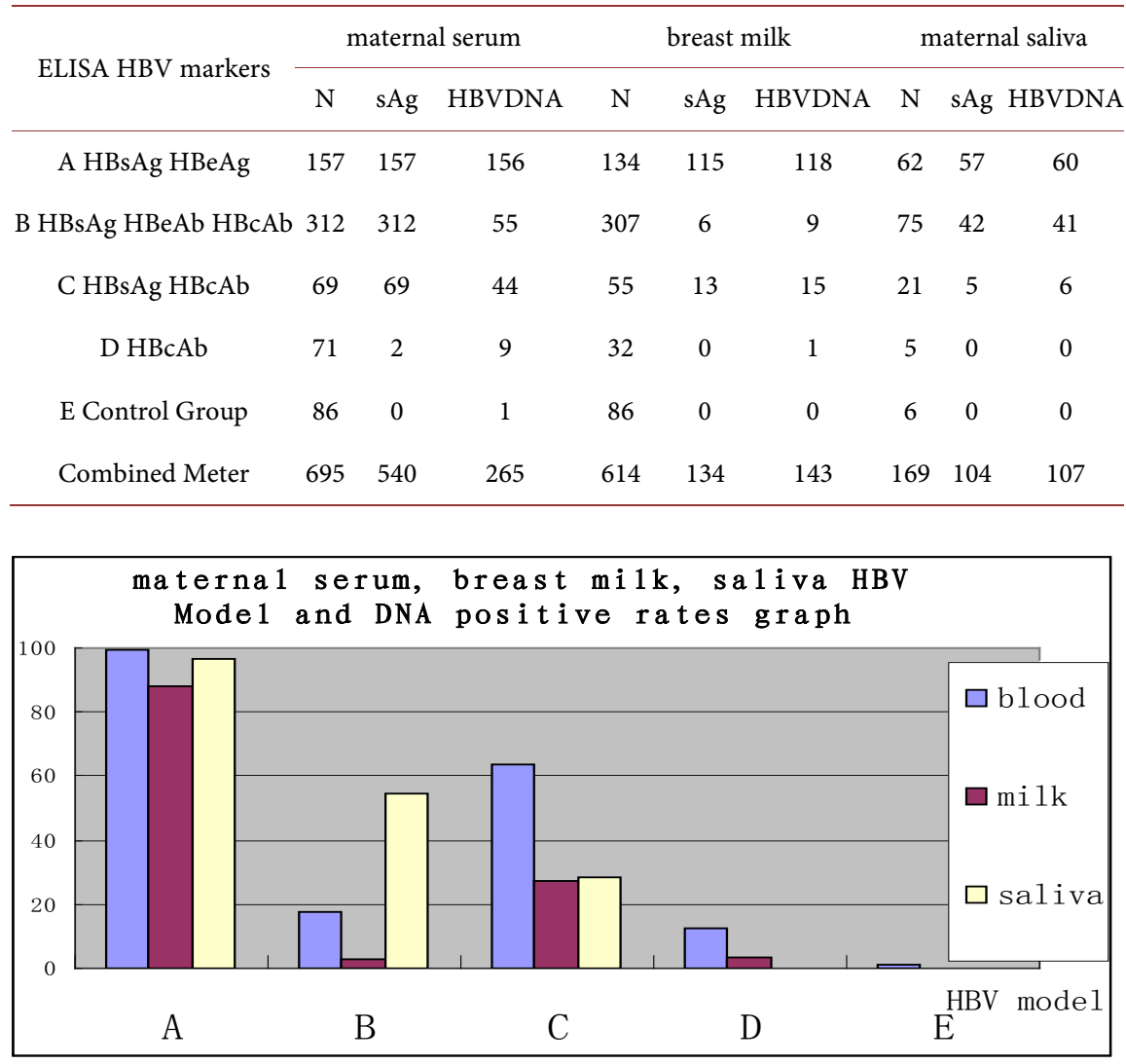


Table 2. 695 cases of maternal serum, breast milk, saliva HBV-DNA maximum value, minimum value table.

\begin{tabular}{ccccccc}
\hline Group & \multicolumn{2}{c}{ maternal serum } & \multicolumn{2}{c}{ breast milk } & \multicolumn{2}{c}{ saliva (copies/ml) } \\
\hline Cases & maximum & minimum & maximum & minimum & maximum & minimum \\
\hline A 157 & $7.12 \times 10^{9}$ & $<1.00 \times 10^{3}$ & $4.26 \times 10^{6}$ & $<1.00 \times 10^{3}$ & $2.97 \times 10^{7}$ & $<1.00 \times 10^{3}$ \\
B 312 & $2.41 \times 10^{7}$ & $<1.00 \times 10^{3}$ & $3.65 \times 10^{4}$ & $<1.00 \times 10^{3}$ & $8.72 \times 10^{5}$ & $<1.00 \times 10^{3}$ \\
C 69 & $1.09 \times 10^{7}$ & $<1.00 \times 10^{3}$ & $2.89 \times 10^{4}$ & $<1.00 \times 10^{3}$ & $6.34 \times 10^{4}$ & $<1.00 \times 10^{3}$ \\
D 71 & $3.18 \times 10^{5}$ & $<1.00 \times 10^{3}$ & $2.17 \times 10^{3}$ & $<1.00 \times 10^{3}$ & $3.56 \times 10^{3}$ & $<1.00 \times 10^{3}$ \\
E 86 & $1.25 \times 10^{3}$ & $<1.00 \times 10^{3}$ & $<1.00 \times 10^{3}$ & $<1.00 \times 10^{3}$ & $<1.00 \times 10^{3}$ & $<1.00 \times 10^{3}$ \\
\hline
\end{tabular}

Table 3. Hepatitis B virus DNA load in maternal serum, breast milk, saliva infection with hepatitis B virus infection status list and graph.

\begin{tabular}{cccccccccc}
\hline Maternal serum group & \multicolumn{2}{c}{ Serum HBV-DNA } & \multicolumn{3}{c}{ milk HBV-DNA } & \multicolumn{2}{c}{ saliva HBV-DNA } \\
\hline Load $($ copies/ml) & $\mathrm{N} 1$ & + & Rate $\%$ & $\mathrm{~N} 2$ & + & Rate $(\%)$ & $\mathrm{N} 3$ & + & Rate $(\%)$ \\
\hline$<1.00 \times 10^{3}$ & 430 & 0 & $0.00(0 / 430)$ & 380 & 0 & $0.00(0 / 380)$ & 20 & 0 & $0.00(0 / 20)$ \\
$(1.00-9.99) \times 10^{3}$ & 59 & 59 & $100(59 / 59)$ & 49 & 1 & $2.04(1 / 49)$ & 4 & 0 & $0.00(0 / 4)$ \\
$(1.00-9.99) \times 10^{4}$ & 22 & 22 & $100(22 / 22)$ & 19 & 5 & $26.32(5 / 19)$ & 21 & 6 & $28.57(6 / 21)$ \\
$(1.00-9.99) \times 10^{5}$ & 25 & 25 & $100(25 / 25)$ & 20 & 11 & $55.00(11 / 20)$ & 25 & 14 & $56.00(14 / 25)$ \\
$(1.00-9.99) \times 10^{6}$ & 27 & 27 & $100(27 / 27)$ & 23 & 16 & $69.57(16 / 23)$ & 27 & 20 & $74.07(20 / 27)$ \\
$(1.00-9.99) \times 10^{7}$ & 83 & 83 & $100(83 / 83)$ & 77 & 65 & $84.42(65 / 77)$ & 49 & 44 & $89.79(44 / 45)$ \\
$(1-9.99) \times 10^{8-9}$ & 49 & 49 & $100(49 / 49)$ & 46 & 45 & $97.83(45 / 46)$ & 23 & 23 & $100(23 / 23)$ \\
Combined Meter & 695 & 265 & $38(265 / 695)$ & 614 & 143 & $23.29(143 / 614)$ & 169 & 107 & $63.31(107 / 169)$ \\
\hline
\end{tabular}

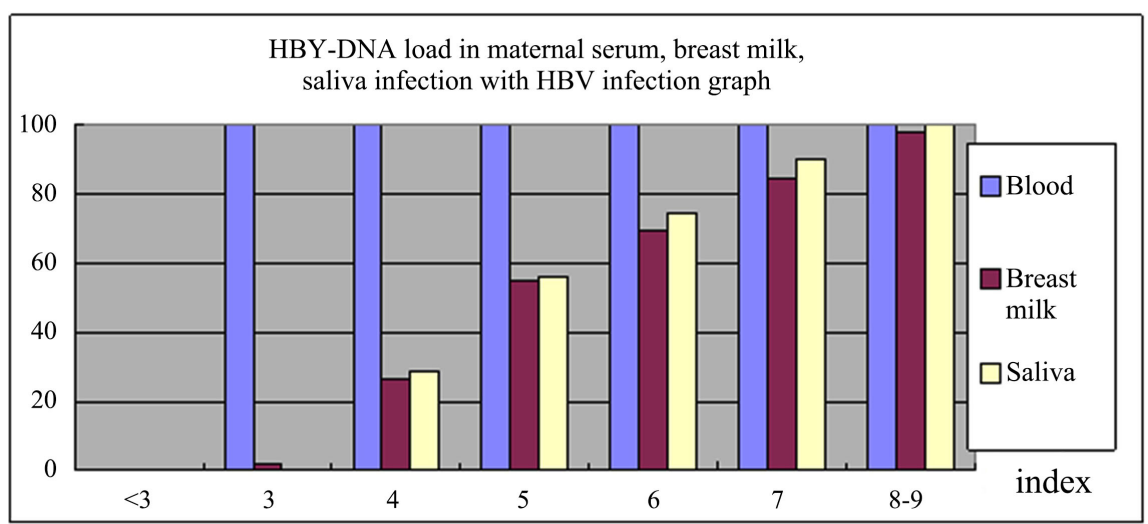

From Table 1, Table 2, Table 3 and graphs statistic obtained HBV-DNA load high maternal milk, saliva, there are potential persistent hepatitis $B$ virus infection risk, but its infectious were lower than the blood; Maternal milk, saliva HBV-DNA loads with blood volume was positively correlated with HBV-DNA ( $\mathrm{r}>0.96 ; \mathrm{P}<0.01$ ); with the serum HBV-DNA load increase in saliva, milk, HBV-DNA positive rate increased, infectivity enhancement. Compared with milk inspection, saliva testing is easier, saliva of hepatitis B virus is less infectious than milk. 
Group E, research of hepatitis B virus five for all negative in 86 cases of maternal serum, breast milk, saliva HBV-DNA diagnostic rate was $1.16 \%(1 / 86), 0 \%$ (0/86), $0 \%(0 / 86)$, maternal serum, breast milk, saliva HBV-DNA load is $<1000$ on average, latex diagnostic positive rate is $0 \%$ the control group, but due to maternal serum diagnostic positive rate was $1.16 \%(1 / 86)$, by tracking with the following diagnosis for the window period, regarding this kind of crowd suggested experimental monitoring of hepatitis B virus markers after making mode of lactation and maternal contact mode of evidence-based medicine.

\section{Discussion}

Implementation of breastfeeding is an important measure for preventing infant health problems; WHO breastfeeding rates are above $80 \%$. On the carriers of the HBV breastfeeding problems, domestic and foreign scholars have different views. The research shows that, HBV replication and strong delivery women such as group A HBsAg HBeAg positive serum and milk are contagious. Studies confirmed the persistence of infection of hepatitis B virus between mother and infant, breast-feeding of infants at increased risk for HBV infection, persistent infection with hepatitis B virus between mother and infant. The implementation of breastfeeding should pay attention to compliance with evidence-based medicine science sex. Hepatitis B virus nucleic acid gene is a reflection of HBV replication, infectious index [3] gold, mother of hepatitis B replication of HBV active milk, saliva HBV-DNA load, and vertical transmission of big risk [4]. The PCR test is a new level of molecule and gene of pathogenic examination method, from the fluorescence quantitative PCR detection of milk HBV-DNA. It reflects that the hepatitis $B$ patients can carry out breast feeding [5]; when maternal blood HBV DNA is $\geq 1000$ copies $/ \mathrm{ml}$, infant feeding is suggested. The mother who carries the hepatitis $B$ virus cannot do maternal infant feeding, and deep kiss intimate contact, in order to prevent blood, saliva and other ways of infection of hepatitis B virus. The parent HBV-DNA content is a dynamic process, so carrying hepatitis B virus lactation to dynamic could detect maternal saliva, milk, so as to take effective measures to reduce the blocking, breastfeeding rates of infection.

Jin Chunzi [6] suggested that sterile or positive HBsAg premarital women should detect HBV-DNA from neonatal serum and milk in premarital and pregnancy period, so as to prevent and block mother-to-child transmission; the content of blood virus could be reduced by taking contraceptive measures, as the HBV-DNA is active before pregnancy [7]; considering the titres decreased after pregnancy, after antiviral treatment for virus, the results obtained with $\mathrm{HBV}$ maternal milk HBV-DNA load are far below the amount of blood group A by HBV-DNA; maternal breast milk transmission of hepatitis $B$ virus and the probability of C group was significantly higher than that of "small Sanyang" maternal. For HbsAg, HbeAg positive maternal is proposed to ban breastfeeding; From the experience of HBsAg positive pregnant women, blood and milk in 
HBV-DNA negative patients, it's suggested that regular lactation dynamic detection, as a maternal infection risk assessment, should be done in maternal blood, saliva, milk, and HBV-DNA. The women of childbearing age should strengthen knowledge propaganda and education of hepatitis $B$, and health of knowledge of project prevention \& treatment. Girls and women at childbearing age should have hepatitis B vaccine; women of childbearing age should do infection screening of HBV. The susceptibility of management and monitoring contributes to selecting the favorable opportunity of pregnancy and production, establish and improve the maternal serum and breast milk in perinatal health care system, detect hepatitis B virus HBV-DNA load model, evaluate the safety of breast-feeding, and guide breast feeding.

Because the hepatitis $B$ virus is mainly spread through blood, baby milk-sucking, HBV-contained blood is also likely to be inhaled. It has been reported that HBV may come into the blood circulation through the capillaries of newborn or infant's oral cavity, pharynx, esophagus, gastrointestinal mucosa, breakage, ulcer, and milk. In occurrence of mastitis and cracked nipples, infant gastrointestinal mucosal edema, inflammation and other pathological conditions, breastfeeding should be stopped immediately; such cases could be recovered after breastfeeding [8] [9]. HBV infection is not safe during the recovery period of maternal milk. It's concluded from the project that if maternal hepatitis immunological detection of HbsAg is positive, the HBV-DNA negative patients should be cautious of lactation, and should be do regular HBV-DNA dynamic test to monitor viral infectious condition, milk. If maternal blood HBV DNA is $\geq 1000$ copies/ml, do not breastfeed; it's suggested that the infants feeding [10] [11] should stop direct feeding, chewing feeding or deep kiss. The mothers carrying the hepatitis B virus cannot do mouth and kiss intimate contact during maternal infant feeding, in order to prevent blood, saliva and other ways of hepatitis B virus infection. Because the saliva of hepatitis B virus DNA content was relatively stable, study of hepatitis B virus should be from the blood through the oral mucosa into the saliva; hepatitis B virus can be directly through the mouth without damage. Ulceration of the mucosa into the blood should be further researched in the future.

Instead of milk inspection, saliva is relatively easy; salivary hepatitis B infection rate is slightly stronger than that of milk. Pregnancy detection of salivary HBV DNA load could provide evidence-based medicine by providing infant feeding patterns and maternal contact mode in advance [12] [13].

Mothers who carry hepatitis B virus should detect maternal saliva and milk during lactation, because the parent HBV DNA content is a dynamic process. Because the viral replication is dynamic change, negative nature cannot guarantee that the whole lactation was negative. Because lactation period is nearly a year, milk and saliva of HBV-DNA load are dynamic changes of hepatitis B virus, i.e., DNA replication, infectious nature. The baby has potential infectious risk of maternal milk, saliva; blood HBV-DNA and HBV-DNA load were positively correlated $(r=0.96 ; \mathrm{P}<0.01)$; with the increasing of the serum HBV-DNA 
load and breast milk, saliva HBV-DNA positive rate is increased, infectivity enhanced. The women of childbearing age should strengthen health knowledge of hepatitis B knowledge propaganda, education, prevention measures, so as to improve the perinatal health care system.

\section{Conflicts of Interest}

The authors declare no conflicts of interest regarding the publication of this paper.

\section{References}

[1] Ma, L., Zhao, G.Z., Liang, Z.L., et al. (2006) Maternal Serum Milk HBV-DNA Load and Breastfeeding Safety Research. China Journal of Modern Medicine, 16, 2851-2855.

[2] The Chinese Medical Association Infectious and Parasitic Diseases Branch (2000) Hepatology. Management of Viral Hepatitis. Zhonghua Ganzangbing Zazhi, 8, 324-329.

[3] Huang, C.Y., Tao, F.B., Yang, L.C., et al. (2010) Hefei Region in 15210 Patients with Hepatitis B Virus Infection Status of Women of Childbearing Age. Chinese Journal of Disease Control, 14, 616-618

[4] Sumazaki, R., Motz, M., Wolf, H., et al. (1989) Detectionof Hepatitis B Virus in Serumusing am Plification of Viral DNA by Means of Poly Merse chainreaction. Journal of Medical Virology, 27, 304-308. https://doi.org/10.1002/jmv.1890270409

[5] Xu, Y.-Y., Liu, H.-H., Zhong, Y.-W., et al. (2015) Peripheral Blood Mononuclear Cell Traffic Plays a Crucial Role in Mother-to-Infant Transmission of Hepatitis B Virus. International Journal of Biological Sciences, 11, 266-273. https://doi.org/10.7150/ijbs.10813

[6] Jia, J.D. and Li, H. (2009) HBsAg and HBV E Antigen and the Clinical Significance of Quantitative Detection. Chinese Journal of Laboratory Medicine, 32, 978-983.

[7] Jia, J.D., Hou, J.L., Yin, Y.K., et al. (2007) Telbivudine and Lamivudine on Hepatitis Curative Effect Forecast Discussion. Zhonghua Ganzangbing Zazhi, 15, 342-345.

[8] Brunetto, M.R., Moriconi, F., Bonino, F., et al. (2009) Hepatitis B Virus Surface Antigen Levels: A Guide to Sustained Response to Peginterferon Alfa-2a in HBeAg-Negative Chronic Hepatitis B. Hepatology, 49, 1141-1150. https://doi.org/10.1002/hep.22760

[9] Wiegand, J., Wedemeyer, H., Finger, A., et al. (2008) A Declinein Hepatitis B VIMS Surface Antigen (HBsAg) Predicts Clearance, But Does Not Correlate with Quantitative HBeAg or HBV DNA Levels. Antiviral Therapy, 13, 547-554.

[10] Zhang, J. and Huang, C.Y. (2012) 553 Cases of Maternal Serum, Breast Milk, Saliva of Hepatitis B Virus-DNA Load Detection and Correlation Research. Journal of Practical Obstetrics and Gynecology, 28, 10-15.

[11] Fang, Y.B., Huang, C.Y., Liu, G.Y., et al. (2011) HBV-DNA of the Milk Ration Specimen Processing Optimization and Clinical Application. Maternal and Child Health Care of China, 26, 2664-2666.

[12] Ni, Z.Z. (2002) Editor of Health Statistics. 4th Edition, People Sanitation Press, Beijing, 114-147.

[13] Lu, H.F., Jin, W.J., Huang, X.H., et al. (2009) In Pregnant Women with Hepatitis B Markers Investigation and Analysis of Intrauterine Infection. Chinese Journal of Experimental and Clinical virology, 23, 235-237. 